\title{
Recognition and recall of verbal material as a function of degree of training'
}

\author{
Roy Laehman and William H. Field \\ STATE UNIVERSITY OF NEW YORK, BUFFALO
}

\begin{abstract}
Abstraet
Since the 19th century, recognition has been accepted as more sensitive than recall in measuring retention, Considerable research supports this conviction which has influenced both pedagogy and experimental psychology. The research below demomonstrates that recognition is superior to recall only at early stages of serial verbal learning. Previous demonstrations of the superiority of recognition are believed to be an artifact of multiple-choice tests which may reflect the elimination of incorrect alternatives rather than recognition of correct alternatives.

\section{Problem}

Experiments comparing recognition to recall, for over 50 years, have yielded higher scores for measures of recognition (Postman \& Rau, 1957). The prevailing view concerning the superiority of recognition is seldom challenged (Davis, Sutherland, \& Judd, 1961) as it is commonplace to recognize successfully a name or word where recall has failed. One limitation on the scope of this generalization is well known. Difficulty of a recognition test is subject to systematic variation by appropriate selection of the incorrect alternatives. Performance on a multiple-choice test, for example, varies inversely with the number of incorrect alternatives per stem, and the homogeneity of the available choices. These difficulties are reduced in a two-choice per item true-false test. Various modifications of the two-choice recognition test are used increasingly to measure short term memory and verbal learning. One variation, the so-called "successive binary recognition test," was recently developed to measure retention of verbal material (Lachman \& Tuttle, 1965). Both training and distracter words were selected from a population of lexical units defined in terms of frequency of occurrence in written English. Again recognition was uniformly superior to free recall for a variety of training lists.

The successive binary test was used in the present experiment to compare recognition to recall throughout the course of acquisition. Traditional multiple-choice tests appear to generate editing behavior on the part of the Ss (Murdock, 1963). Response alternatives for a given stem are systematically eliminated until one remains or one is selected from the remaining alternatives. Since the binary recognition procedure precludes editing and other secondary habits, a relatively pure measure of recognition is obtained, and perhaps even a clearer indication of the memory trace. Considerations of the nature of serial learning suggested that the prevailing generalization concerning recognition is incorrect.

\section{Method}

The present experiment consisted of two phases: training followed by either a free recall or recognition test. The training list consisted of 50 different words (type-token ratio $=1.0$ ) selected from the 1,000 most frequent English words (Thorndike \& Lorge, 1944). Each word was presented alone but the order was constant and at a high approximation to English (i.e., prose). A training trial consisted of one exposure of the entire list. Independent groups of Ss received 1, 2, $4,8,16,32$, and 128 trials. The inter-trial interval was $60 \mathrm{sec} . \mathrm{Ss}$ in the 32 and 128 trial groups were given a 5 min. rest between trials 16 and 17. The 128 trial Ss, however, were trained for four consecutive days with 32 trials administered each day. Each word was printed on a separate IBM card. The Ss exposed one word and covered the previous word every $1.5 \mathrm{sec}$. by turning the cards in time with clicks from a tape recorder. Training groups were subdivided for free recall or recognition testing. Immediately after training, the assigned testing procedure was described and Ss in the free recall condition wrote down all words remembered. Word order on the test was optional and no time limit was imposed. Fifty new words were sampled from the same language population for the recognition test. These distracter words were mixed randomly with the training words. One card containing one word was sorted every $1.5 \mathrm{sec}$. into "recognize" or "don't recognize" categories. The Ss were 130 introductory psychology 'students.

\section{Results and Diseussion}

The results are presented graphically in Fig. 1. Percentages of words correctly recalled and recognized are plotted against training trials in the upper section of the graph. False positive errors, words not on the training list that were recalled or recognized, are plotted at the bottom. Each data point represents the scores for an independent group of $10 \mathrm{Ss}$ with the exception of the 128 trial conditions. These $10 \mathrm{Ss}$ were tested first for recognition followed immediately by free recall. Recognition and recall scores were compared by the Mann-Whitney U-test for $M_{1}=M_{2}=10$ : trial $1 \mathrm{U}=0, \mathrm{p}<.001$; trial $2 \mathrm{U}=12.5, \mathrm{p}<.01$; trial $4 \mathrm{U}=25.0$; trial $8 \mathrm{U}=54.5$; trial $16 \mathrm{U}=0, \mathrm{p}<.001$; trial $32 \mathrm{U}=0$, $\mathrm{p}<.001$. The 128 trial distributions were compared by the randomization test for matched pairs, $p<.01$. Recognition is superior only during the initial stages 


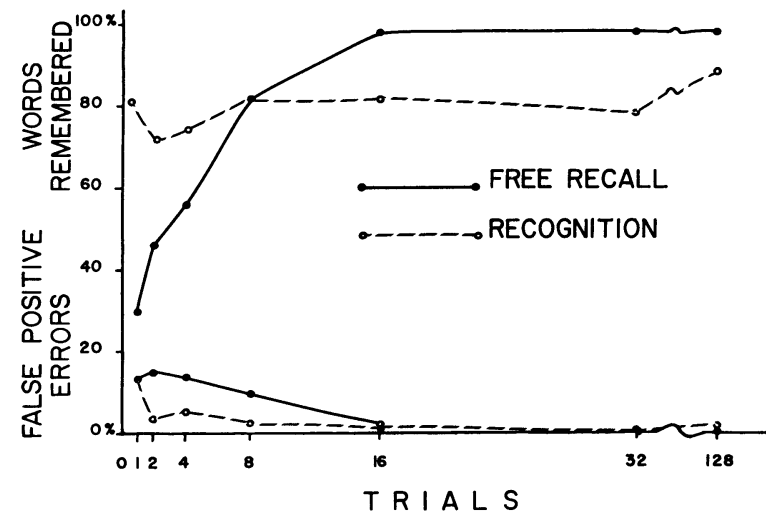

Fig. 1. Mean percentage correct (above) and false positive errors (below) as a function of number of training trials and the type of retention test.

of learning. Recall, following trial 8 , is uniformly superior to recognition. There is, in fact, zero overlap between the recall and recognition distributions on trials $1,16,32$, and 128 . The increase in recognition scores between trial 32 and 128 may not be due to additional training but rather to motivational factors. It was of interest to determine whether recognition would ever reach the $100 \%$ correct level. Thus, Ss in the 128 trial treatment, unlike the rest of the sample, were paid for their services and repeatedly subjected to threats and pleading to keep them concentrating during long and tedious training periods.

Roughly $80 \%$ of the individual words are correctly recognized at all stages of training. Perhaps learning, in the conventional sense of the concept, is not measured by recognition. It is equally likely that during serial verbal learning, individual words are not learned as such but larger units are being stored in the brain. Yet in some fashion, the recognition Ss rapidly learn what is not on the training list as false positive errors drop sharply after the first training trial. The view, so long held by psychologists, concerning the general superiority of recognition was perhaps due to our failure to notice that the capacity for elimination of incorrect alternatives may be superior to the ability to recognize correct alternatives on a multiple-choice test.

\section{References}

DAVIS, R., SUTHERLAND, N. S., \& JUDD, B. R. Information content in recognition and recall. J. exp. Psychol., 1961, 61, 422-429.

LACHMAN, R., \& TUTTLE, A. V. Approximations to English and short term memory: Construction or storage? J. exp. Psychol., 1965 , in press.

MURDOCK, B. B., JR. An analysis of the recognition process. In C. N. Cofer \& B.S. Musgrave (Eds.), Verbal behavior and learning. New York: McGraw-Hill, 1963.

POSTMAN, L., \& RAU, L. Retention as a function of the method of measurement. U. Calif. Publ. Psychol., 1957, 8, 217-270.

THORNDIKE, E. L., \& LORGE, I. The teacher's word book of 30,000 words. New York: Columbia Univ. Press, 1944.

\section{Note}

1. Supported by $\mathrm{MH} 10764-01$; the training list is available upon request. 